\title{
Effect of Nanocurcumin and Curcumin on Cisplatin-Induced Acute Kidney Failure
}

\author{
Bashar A. W. Pandhita, Nielda K. Sumbung, Deliana N. I. Rahmi, Bernardino M. Waworuntu, \\ Melva Louisa, Vivian Soetikno
}

Pharmacology and Therapeutics, Faculty of Medicine, University of Indonesia, Indonesia

Background: Nephrotoxicity is a limiting factor of the platinum-based chemotherapeutic drug cisplatin. One third of patient treated with cisplatin eventually develop acute nephrotoxicity due to accumulation of cisplatin in renal tubular cell which causes oxidative stress and DNA damage. Curcumin is the active ingredient of Curcuma longa, which is reported to exhibit anti-inflammatory property and nephroprotective property, despite its low bioavailability. To increase its bioavailability, nanocurcumin can be used instead. This study aims to know the difference between administration of curcumin and nanocurcumin on cisplatin induced acute nephrotoxicity.

Methods: Nanocurcumin and curcumin were used in this study on rat model of AKI which induced by cisplatin $(\mathrm{n}=25)$ and observe the expression of Nrf2 and Keap1, Oct2 and Ctr1, Kim-1 and Ngal, and curcumin concentration in kidney tissues of rats. Rats were divided into five groups randomly: (1) Control, (2) Cisplatin $(7 \mathrm{mg} / \mathrm{kgBW}$ single dose), (3) Cisplatin + Curcumin $(7 \mathrm{mg} / \mathrm{kgBW}$ single dose $+100 \mathrm{mg} / \mathrm{kg} /$ day $)$, (4) Cisplatin $+50 \mathrm{mg}$ Nanocurcumin $(7 \mathrm{mg} / \mathrm{kgBW}$ single dose $+50 \mathrm{mg} / \mathrm{kg} /$ day $)$, (5) Cisplatin $+100 \mathrm{mg}$ Nanocurcumin $(7 \mathrm{mg} / \mathrm{kgBW}$ single dose $+100 \mathrm{mg} / \mathrm{kg} /$ day $)$. qRTPCR was then conducted to calculate the relative expression of the genes. LCMS/MS was used to analyze curcumin and nanocurcumin concentration in kidney tissues.

Results: There was no significant difference between groups in expression of Nrf2 and Keap1 gene, although there is an increase in Keap1 expression in rats treated with $100 \mathrm{mg}$ nanocurcumin. There was also no significant difference in expression of Oct2 and Ctr1 gene, although administration of 100mg Nanocurcumin increases Oct2 gene expression. Kidney damage markers (Kim-1 and Ngal) were also not significantly different between groups, although rats treated with $100 \mathrm{mg}$ of Nanocurcumin express lower level of Kim-1 and Ngal. We also found that nanocurcumin $100 \mathrm{mg}$ has a highest concentration accumulation in the kidney tissues compared to that of other groups.

Conclusion: Our conclusion is that nanocurcumin have better nephroprotective effect compared to curcumin shown by increase in Keap1 and Oct2 with decreased Kim-1 and Ngal expression in rats treated with $100 \mathrm{mg}$ nanocurcumin at least in part due to increase concentration of $100 \mathrm{mg}$ nanocurcumin in kidney tissues. 